\title{
Research on Blended Learning Mode Based on the Course of Engine Principle
}

\author{
Fei Wu", Man Hu, Yunwu Li, Jie Ji \\ College of Engineering and Technology, Southwest University, Chongqing, China
}

\section{Email address:}

wufeifrank@126.com (Fei Wu)

${ }^{*}$ Corresponding author

\section{To cite this article:}

Fei Wu, Man Hu, Yunwu Li, Jie Ji. Research on Blended Learning Mode Based on the Course of Engine Principle. Science Journal of Education. Vol. 8, No. 3, 2020, pp. 82-86. doi: 10.11648/j.sjedu.20200803.13

Received: May 1, 2020; Accepted: June 4, 2020; Published: August 5, 2020

\begin{abstract}
This article deals with the problem of low participation of students as well as their poor understanding in the course of "Engine Principle". In this paper, the current situation and characteristics of the curriculum are analyzed. With the advantages of MOOC, the authors tend to explore blended learning model, which is composed of online knowledge obtaining and offline flipped class. The design and practice of the model is implemented in three aspects: teaching contents, class organization and assessment. We recorded teaching videos and related course materials based on knowledge points and uploaded them to the Mooc platform. Tests run through the whole training process in each stage in order to evaluate the effect of blended learning mode. This blended learning model has balanced traditional teaching and modern teaching advantage. Furthermore, the ability of students to put what they have learned into practice and the ability to innovate has been promoted. With the blended learning mode based on MOOC, it is a better way to solve the problems of low participation and poor understanding and application ability of students in the current teaching.
\end{abstract}

Keywords: Engine Principle, MOOC, Blended Learning Model

\section{Introduction}

Emerging Engineer Education is an important strategy and deployment of engineering education reform in Higher Engineering Education of China [1]. Under the background of new engineering, how to train engineering talents with high practical ability and innovation ability through effective curriculum construction, and how to realize the high docking between talent training and market demand, has become an important issue needed to be solved in the current curriculum construction process. With the reform of traditional teaching mode, online courses and blended learning mode based on online courses emerge as the times require. The enhancement of the construction of online courses will not only improve the quality and the level of teaching, but also promote the reform and development of the whole course system [2]. The course of Engine principle is a required professional basic course for college students majoring in vehicle engineering with 2.5 credits and 36 class hours. The course is designed for undergraduates majoring in vehicle engineering and related majors, with a student number of more than 120 annually. This course mainly studies the working principle and related knowledge of the car engine.

\section{Current Situation Analysis of Curriculum}

The characteristics of the course Engine principle are the complicated content, deep theory, abstract and difficult to understand. It is closely related to the actual production and life, and it has strong practicability. However, due to the limitations of teaching form and teaching resources, there are still some problems in current curriculum.

(1) The teaching method in the classroom is homogeneous and the participation of students is low. PPT slides are still the teaching carrier of the curriculum, and knowledge infusion is the main form. As the central interpreter, the teacher does not fully establish the main position of students to experience the active participation, discovery, exploration and knowledge construction. Therefore, most students learn knowledge passively since their enthusiasm is low. Finally, their ability of 
self-directed learning is not exercised. With the development of education and teaching technology, the reform of teaching methods and means should be actively explored in the course of engine principle. Using computer technology, multimedia, other information technology and modern Internet tools, we aim to expand the content of knowledge in this course, enhance the participation of students in the classroom, and improve the efficiency of teaching.

(2) Limited source of knowledge acquisition. The traditional teaching in the classroom is limited by time and space, so the repetitive explanation of knowledge is not efficient, also the channel for students to acquire knowledge is relatively narrow. Online learning uses videos to make a diversity combination across time and space. Students can preview the content before class, and through online learning students can access more knowledge and news for the discussion in class. During the course, the difficulties in the teaching extent can be explained by the teacher. After class, online homework and online discussion can be carried out to extend the access of the knowledge of students.

\section{Blended Learning Mode Based on MOOCs}

\subsection{The Essence and Development of MOOC}

MOOC (Massive Open Online Course) was first proposed by Canadian scholars Dave Cormier and Bryan Alexander [3]. The essence of MOOC education is based on the sharing of "online open curriculum" resources by modern network technology tools such as digital learning platform to realize the practice process of personalized construction. Its advantages lie in the openness of network technology, the reduction of teaching cost, the sharing of teaching resources, the crossing of subject resources and the pluralism of evaluation, which construct a complete and pluralistic teaching ecosystem [4]. Therefore, MOOC is quickly appreciated and supported by educational researchers and curriculum experts from all countries as soon as the concept of MOOC was proposed [5].

Since the concept of MOOC was put forward in 2008, the world-famous universities such as Princeton University, MIT and Stanford University have successively launched relevant MOOCs, leading the rise of MOOCs in the world [6]. In the field of higher education, then there is a wave of reform aiming at reducing the cost of education, promoting education equity and serving lifelong learning [7]. In recent years, there has been a great development of MOOCs in China, and excellent MOOCS platforms such as China University MOOC and Xuetang online have emerged one after another. These platforms provide free courses for the society, and each platform also actively cooperates with colleges and universities across the country, trying to provide SPOC (small private oline course) and other teaching services to explore the teaching mode in China [8]. According to incomplete statistics, by the end of 2016 the total number of online courses constructed by colleges and universities in China has exceeded 1400 with more than 1700 schools and 30 million students participating [9]. Through MOOCs the cooperation of teaching and scientific research among university teachers has been enhanced. The University Alliance of credit mutual recognition, resource construction, talent training and cooperative teaching and research has been further promoted.

\subsection{Blended Learning Mode}

At present, with the advantages of traditional classroom and information technologies, the professional courses in colleges and universities mostly adopt blended learning, that is, learning professional knowledge through online Moocs and meeting teachers and students offline to discuss and study [10]. According to the research, passive listening can only master $20 \%$ of the knowledge at most, and $90 \%$ knowledge can be learned through discussion, evaluation and teaching. In blended learning, students learn the basic knowledge of the course through video online before class, then they discuss and study the difficulties and doubts they encountered in the classroom. Teachers no longer focus on teaching, but to train students' ability of knowledge application by simulating enterprise projects. The blended learning method makes the students become the masters of the class [11]. It also urges the students to preview actively before class and discuses actively in class, stimulates the sense of achievement for students, and finally achieves the purpose of active participation [12]. MOOC platform generally has the functions of learning analysis and supervision, unit test automatic correcting (objective questions), message push, online forum interaction, student scoring, etc [13]. Teachers can supervise the overall learning state of students at any time and adjust the content and progress of teaching activities in time to ensure the teaching effect [14]. Students can speed up or repeatedly watch teaching videos according to the learning requirements of students at different levels. The interactive function of the platform can also provide a good communication between teachers and students, and improve the participation of students [15].

\section{Curriculum Design of Blended Learning Mode}

\subsection{Teaching Mode}

The course of engine principle makes full use of multi-media classroom, MOOC platform, experimental training base and other teaching environments with the help of the blended learning mode of "online video learning + offline flipped classroom". Students firstly can learn the basic knowledge by watching the video before class and complete the self-test questions set on the platform. Through the data analysis of the platform, teachers can grasp the data of the learning and their common mistakes, then focus on the explanation and guidance in the classroom teaching. Students will be divided into several groups, then discuss, collaborate and finally complete the teaching tasks. In the offline 
classroom, teachers are mainly responsible for organizing work, commenting and guiding students' ideas and plans appropriately for ensuring the completion progress of the teaching target. For some chapters requiring practical operation, the method of "practical video learning + practical operation" is adopted.

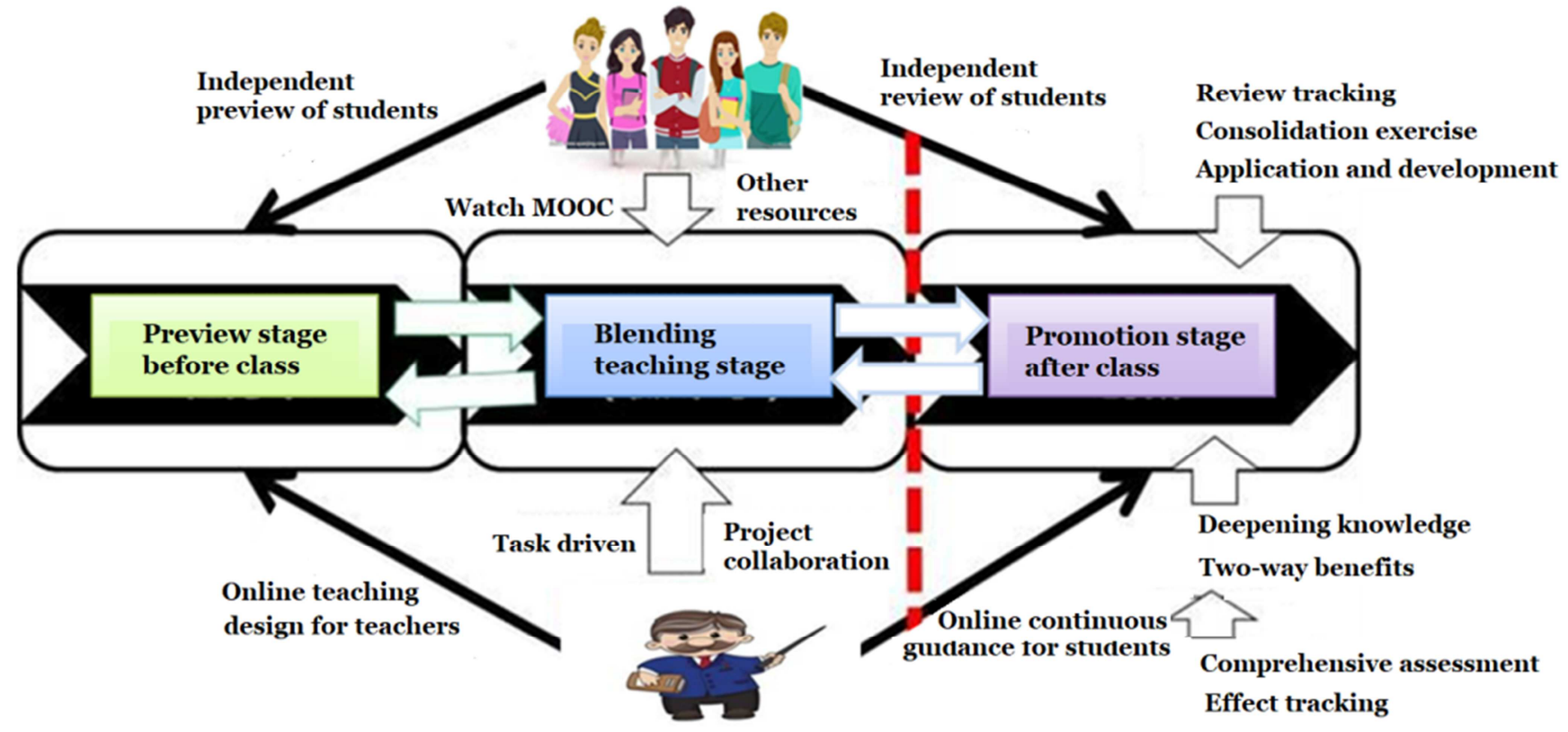

Figure 1. The blended learning mode based on MOOC resources.

\subsection{Content of Courses}

According to the teaching objectives of the course "principles of engine", the teaching procedures and methods of each unit are designed, including three stages: before class, during class and after class. Each stage includes the main tasks (project activities), processes and the application and output of curriculum resources that teachers and students need to carry out. We recorded teaching videos and related course materials based on knowledge points and uploaded them to the Mooc platform.

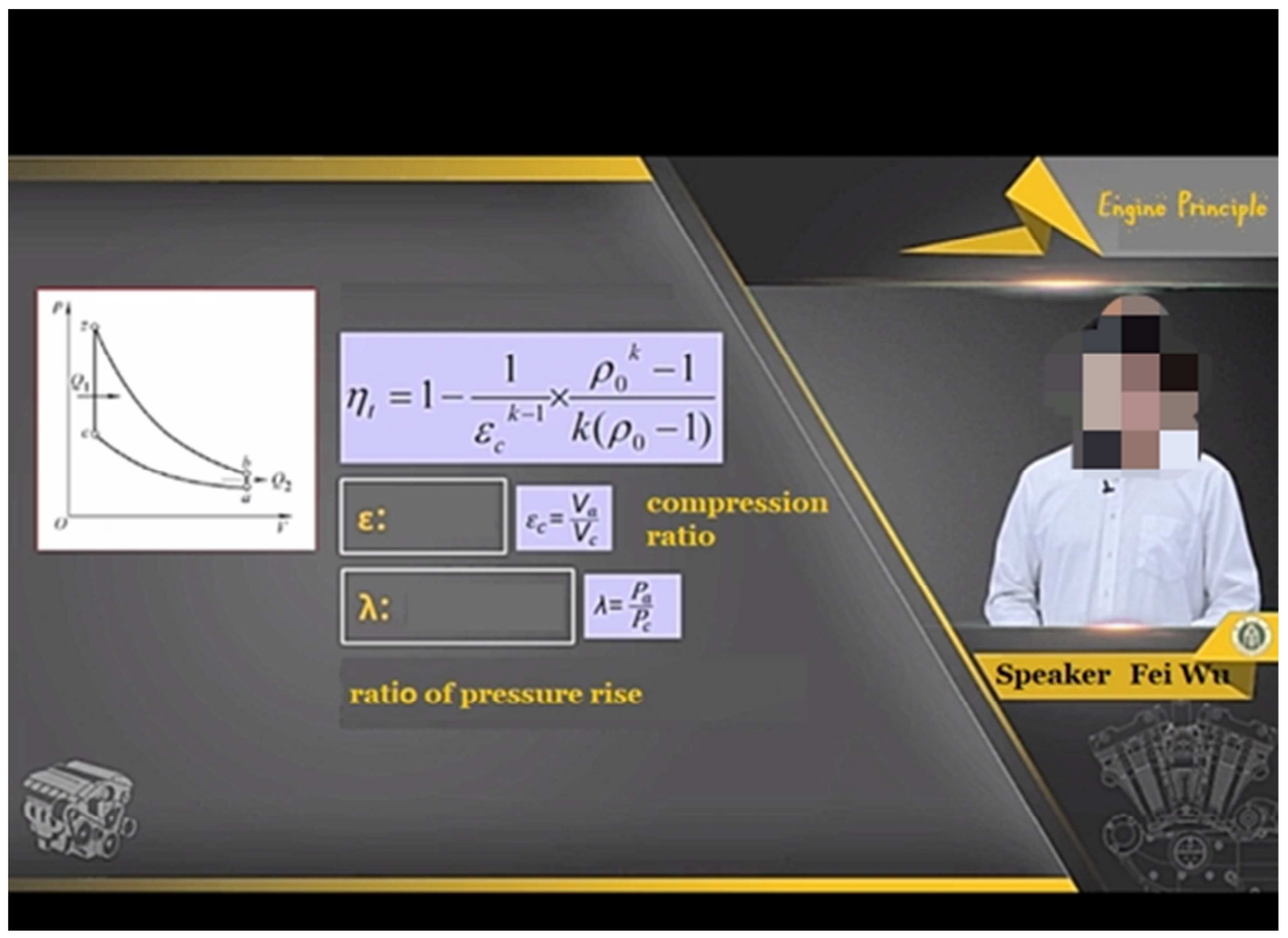

Figure 2. Video picture from Mooc. 

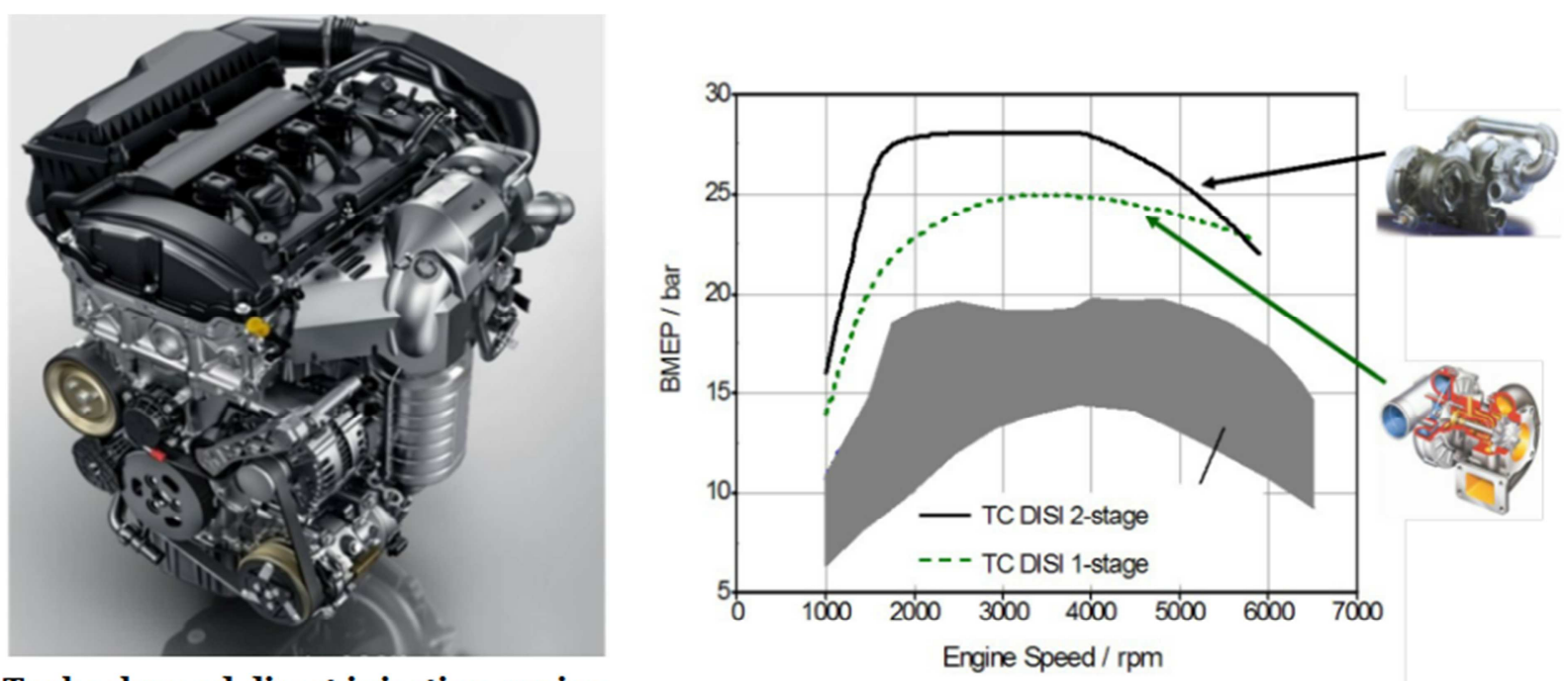

Turbocharged direct injection engine

Figure 3. Pictures from the Mooc of the course of engine principle.

\subsection{Assessment Method}

The tests of this course try to reveal the level and ability of the students of their understanding, mastering and application of the knowledge they have learned. We focus on the ability of students to understand the problems related to engine principle and their ability to acquire new knowledge and skills in this field. The final examination is no longer the only evaluation standard in the assessment of this course. Tests run through the whole training process in each stage. Through the completion of the task and the performance of display and explanation, the tests focus on the ability of knowledge application, thinking and expression of students. The final score of each student is comprehensively evaluated according to his performance during the course, the evaluation of other students and the final examination in order to let the students spend their time in the ordinary times. Therefore, The final score of each student can be allocated as follows: total score $(100 \%)=$ final exam score $(50 \%)+$ assignment completion score $(40 \%)+$ student's activity reward (10\%).

\subsection{Reflection}

With the blended learning mode adopted in this course, the satisfaction of students to the blended learning mode is over $85 \%$, which shows that this mode is accepted by students and the teaching performance is improved. However, there are still some problems that need to be solved.

1. Learning purpose should be clearer. Teachers should guide students to deepen their understanding of knowledge and digest the unabsorbed knowledge.

2. Teaching in classroom should be more profound. Classroom teaching is no longer based on knowledge infusion, but focuses on guiding students to understand and apply knowledge. Thoughtful design of the key and difficult situations or problems of the course is conducive to improve the participation and enthusiasm of students in learning and strengthening the knowledge.

3 The organization ability of teachers needs to be improved in the teaching process. In the face of a large number of classroom communication online and offline, teachers often fail to pay attention to the discussion and communication of each student in time and conduct guidance. The effect of discussion and project teaching needs to be further improved.

\section{Conclusion}

According to the characteristics and training requirements of the course of engine principle, the blended learning mode based on MOOC can provide a better way to solve the problems of low participation and poor understanding and application ability of students in the current teaching. This model can reduce a lot of simple repetitive work of teachers. therefore, the teachers can spare more time in classroom teaching, especially for the activities that students are most interested in and most valuable: To guide students to learn independently and solve problems in cooperation. The high-quality MOOC platform can make teachers and students have a better teaching feedback and learning adjustment. On the other hand, in order to achieve the ideal training effect in the curriculum teachers and students need more investment, including self-motivation, self-discipline, efficient self-control and management time, online learning and collaboration ability, etc., which need further practice and discussion in the subsequent teaching activities.

\section{Acknowledgements}

The authors wish to thank the support by Scientific and Technological Research Program of Chongqing Municipal Education Commission (Grant No 183168), the Education and teaching reform research Program of Southwest University (Grant No. 2018JY020) and Fund of innovation and entrepreneurship education reform of Chinese Universities (Grant No. 2019CCJG01Z001). 


\section{References}

[1] Denghua Zhong. Connotations and Actions for Establishing the Emerging Engineer Education $[\mathrm{J}]$ Research in Higher Education of Engineering, 2017 (03): 7-12.

[2] Cong X. To Cultivate Engineer with Instrumental Rationality and Value Rationality - on the Goal of Emerging Engineering Education (3E) [J]. Research in Higher Education of Engineering, 2017.

[3] Tendencies towards DEEP or SURFACE learning for participants taking a large massive open online course (MOOC) [C]. frontiers in education conference, 2015: 1-4.

[4] Pursel B K, Zhang L, Jablokow K W, et al. Understanding MOOC students: motivations and behaviours indicative of MOOC completion [J]. Journal of Computer Assisted Learning, 2016, 32 (3): 202-217.

[5] Smith N, Caldwell H, Richards M, et al. A comparison of MOOC development and delivery approaches [J]. international journal of information \& learning technology, 2017, 34 (2): 152-164.

[6] G. Matkin. MOOC RESEARCH: WHAT CAN WE LEARN AND HOW? [J]. Iated, 2014.

[7] Castillo N M, Lee J, Zahra F T, et al. MOOCs for Development: Trends, Challenges, and Opportunities [J]. Information Technologies and International Development, 2015, 11 (2): $35-42$.
[8] Zhaohui, Gong. The development of medical MOOCs in China: current situation and challenges. [J]. Medical Education Online, 2018.

[9] Chenglin H, Jianwei C. SWOT Analysis on the Development of MOOC in China's Higher Education [J]. American Journal of Educational Research, 2016, 4 (6): 488-490.

[10] Keson C. Practical Research on Blending Teaching and Studying Mode of Microcomputer Principles and Interface Experiment [J]. Experiment Science and Technology, 2012.

[11] Sharma, P. Blended learning [J]. ELT Journal, 2010, 64 (4): 456-458.

[12] Hou S, Chen S. Research on applying the theory of Blending Learning on Access Database Programming Course teaching [C]. international conference on education technology and computer, 2010.

[13] Ginns P, Ellis R A. Quality in blended learning: Exploring the relationships between on-line and face-to-face teaching and learning [J]. Internet and Higher Education, 2007, 10 (1): 53-64.

[14] Pereira J A, Pleguezuelos E, Meri A, et al. Effectiveness of using blended learning strategies for teaching and learning human anatomy [J]. Medical Education, 2007, 41 (2): 189-195.

[15] Sejdiu S. English language teaching and assessment in blended learning [J]. The Journal of Teaching and Learning, 2014, 3 (2): 67-82. 